\title{
Differences in plasma amino acid levels in patients with and without bacterial infection during the early stage of acute exacerbation of COPD
}

This article was published in the following Dove Medical Press journal: International Journal of COPD

\author{
Saki Inoue' \\ Hideki Ikeda ${ }^{2}$ \\ 'Department of Nutritional \\ Management, Sanyudo Hospital, \\ Yonezawa, Japan; ${ }^{2}$ Pulmonary Division, \\ Department of Internal Medicine, \\ Sanyudo Hospital, Yonezawa, Japan
}

Purpose: No consensus has been reached regarding appropriate nutritional intervention and rehabilitation during early acute exacerbation of COPD (AECOPD). Given the individual differences in symptoms of AECOPD, patients should be classified by their pathology. For example, it is known that there are differences in the inflammatory response between AECOPD with and without bacterial infection. However, there have been few reports on AECOPD from a nutritional perspective. The aim of this study was to investigate amino acid levels in patients with AECOPD.

Patients and methods: Blood was collected from patients who were hospitalized with AECOPD and from patients with COPD that was in a stable state. We divided the patients with AECOPD into those without bacterial infection (group A) and those with bacterial infection (group B). The patients with COPD that was stable served as controls (group C). The plasma levels of 9 essential amino acids, 13 nonessential amino acids, and total amino acids were compared between the three groups.

Results: In the early stages of AECOPD, differences in plasma levels of only three amino acids (glycine, phenylalanine, and arginine) were observed between groups $\mathrm{C}$ and $\mathrm{A}$. Differences in total amino acids and 13 amino acids were observed between groups $\mathrm{C}$ and B. Group B had lower levels of total amino acids and of seven amino acids (asparagine, citrulline, glutamine, histidine, methionine, serine, and threonine) compared with the other study groups.

Conclusion: The findings of this study show that amino acid levels in plasma differ in patients with AECOPD depending on whether or not bacterial infection is present. Our results suggest that specific amino acids (ie, asparagine, citrulline, glutamine, histidine, serine, and threonine) have potential utility as diagnostic markers to distinguish between bacterial and nonbacterial AECOPD.

Keywords: COPD, acute exacerbation, amino acid, bacterial infection

\section{Plain language summary}

It has been reported that the increases in inflammatory cytokine levels that occur in acute exacerbation of COPD (AECOPD) with bacterial infection differ from those in AECOPD without bacterial infection. We speculated that the metabolism of amino acids was also different between AECOPD with and without bacterial infection and felt that a distinction between the two was necessary for appropriate rehabilitation and/or nutritional interventions. In this study, we measured plasma amino acid levels in patients with stable COPD and acute-phase plasma amino acid levels in patients hospitalized for AECOPD. We found that levels of certain amino acids decreased in AECOPD with bacterial infection. Our results suggest that specific amino acids (ie, asparagine, citrulline, glutamine, histidine, methionine, serine, and threonine) have potential utility as diagnostic markers to distinguish between bacterial and nonbacterial AECOPD.
Correspondence: Hideki lkeda Pulmonary Division, Department of Internal Medicine, Sanyudo Hospital, Chuo 6-I-2I9, Yonezawa,

Yamagata 992-0045, Japan

Tel $+8 \mid 238243700$

Fax +8I 238243709

Email h-ikeda@js3.so-net.ne.jp
International Journal of COPD 2019:14 575-583

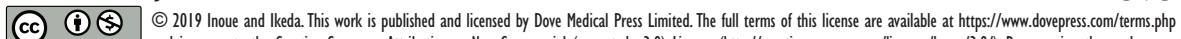
cc) hereby accept the Terms. Non-commercial uses of the work are permitted without any further permission from Dove Medical Press Limited, provided the work is properly attributed. For permision for commercial use of this work, please see paragraphs 4.2 and 5 of our Terms (https://www.dovepress.com/terms.php). 


\section{Introduction}

Acute exacerbation of COPD (AECOPD) is known to accelerate the decline in quality of life and lung function that occurs in patients with COPD, resulting in deterioration of the prognosis. ${ }^{1}$ Bacterial ${ }^{2}$ and viral $^{3}$ infections are important etiologic factors in AECOPD. ${ }^{4}$ However, there have been reports of differences in increases in IL-6 and other inflammatory cytokines in patients with AECOPD depending on whether or not bacterial infection is present. ${ }^{5}$ Differences in amino acid levels have also been reported in patients with influenza, a viral infection, according to whether there is concomitant bacterial infection. ${ }^{6}$ Systemic inflammation associated with infection results in loss of appetite, and in order to compensate, the protein needed for gluconeogenesis is recruited from the muscles and dermal tissues. ${ }^{7}$ The changes in amino acid levels that occur in response to loss of appetite have been reported to differ between patients with and without bacterial infection. ${ }^{7}$ Therefore, even in patients who meet the commonly accepted criteria for AECOPD, ${ }^{8,9}$ differences in amino acid metabolism between those with and without bacterial infection would be expected. However, according to the GOLD, in relation to management of AECOPD, causes are classified solely on the basis of the criteria for administration of antibiotics. ${ }^{10}$ Respiratory rehabilitation and nutritional intervention have previously been implemented in patients with COPD that is in a stable state, ${ }^{11-14}$ but rarely in patients in the early stages of AECOPD, ${ }^{15,16}$ for whom there is currently no consensus regarding appropriate rehabilitation and nutritional intervention. A negative report on the efficacy of nutritional supplementation during the early stage of AECOPD did not distinguish between cases with and without bacterial infection, ${ }^{17}$ and the studies on rehabilitation during the early stage of AECOPD similarly did not make this distinction. ${ }^{15,16}$

We considered these opposing results to be based on the lack of a clear method or markers to distinguish between bacterial and nonbacterial AECOPD, and the lack of reports in which differences in nutritional status or amino acid metabolism in patients with AECOPD were noted. In this study, we measured acute-phase plasma amino acid levels in patients hospitalized for AECOPD with the objective of providing a landmark for research about nutritional status or amino acid metabolism in patients with AECOPD.

\section{Patients and methods}

Subjects were diagnosed to have COPD if they had a history of smoking ( $\geq 10$ pack-years) and evidence of an obstructive pulmonary disorder on a lung function test (percentage of forced expiratory volume in 1 second for forced vital capacity $\left.\left[\mathrm{FEV}_{1} \%\right]<70 \%\right)^{10,18}$ AECOPD was diagnosed according to the ASPEN, ${ }^{9}$ GOLD, ${ }^{10}$ and Japanese Respiratory Society guidelines for the diagnosis and treatment of COPD. ${ }^{18}$ This study was approved by the ethics committee of Sanyudo Hospital. Written informed consent was obtained from each patient, in accordance with the tenets of the Declaration of Helsinki. These processes were performed in accordance with the ethical guidelines for medical and health research involving human subjects ${ }^{19}$ set out by the Ministry of Health, Labor and Welfare in Japan. Patients with diabetes (HBA1C $>6.1$ or receiving treatment for diabetes), chronic renal failure (estimated glomerular filtration rate $<60 \mathrm{~mL} / \mathrm{min} / 1.73 \mathrm{~m}^{2}$ ), a history of gastric resection, or terminal illness were excluded from all the study groups.

The AECOPD study population consisted of patients who were hospitalized in our Pulmonary Division of Internal Medicine from March 2016 to April 2018 and met the diagnostic criteria for AECOPD. Patients who visited the hospital as outpatients from April to June 2018 and had not suffered an acute exacerbation in the previous 3 months were considered to have COPD that was stable and were enrolled in group $\mathrm{C}$.

Patients in the AECOPD group with the following features were diagnosed as having bacterial infection (pneumonia, group B): expectoration of purulent sputum;, ${ }^{4,20}$ an increased white blood cell count or C-reactive protein level on hematology tests; ${ }^{5}$ opacity on thoracic radiography or computed tomography; febrile symptoms; ${ }^{21,22}$ and detectable etiologic bacteria. Patients who did not display any of these features, except for fever, were deemed to have AECOPD without bacterial infection and were enrolled in group A. Sputum was collected from every patient and was screened with Gram's stain method. Bacteria were cultured with sheep blood agar, chocolate agar, mannitol salt agar with egg yolk, and modified DRIGALSKI agar.

In the AECOPD group, we collected blood between $2 \mathrm{pm}$ and $3 \mathrm{pm}$ within 24 hours of admission, ie, 2-3 hours after eating for subjects who were permitted to eat. The nutritional manager planned all menus served from our nutrition division. The lunch menu for COPD patients was regulated to contain $600 \mathrm{kcal}, 25 \mathrm{~g}$ of protein, and 80-100 g of carbohydrates. The nutritional manager measured leftover food from each served meal, and calculated the eating rate with food consumed expressed as a percentage of total food served to the patient. The control group was allowed to consume water only from $9 \mathrm{pm}$ on the previous day and underwent blood collection on an outpatient basis at $9 \mathrm{am}$. Immediately after 
collection, each blood sample was placed in a test tube containing EDTA-Na $\mathrm{Na}_{2}$ and then transferred on ice to the testing laboratory, where it was immediately centrifuged and the plasma obtained was stored frozen at $-40^{\circ} \mathrm{C}$. Thirty-eight amino acids were subsequently analyzed by SRL Inc. (Tokyo, Japan) using liquid chromatography-mass spectrometry. We obtained the plasma levels of 9 essential amino acids and 13 nonessential amino acids from the reports supplied by SRL Inc. Because patients with AECOPD (groups A and B) were not fasted, we conducted a survey of eating rates based on the medical records.

The three groups were compared using a nonparametric multiple comparison test (the Steel-Dwass method). We used chi-squared tests for the three-group sex ratio and the twogroup comparison of eating rates. Relationships between body mass index (BMI), albumin, or percentage of predicted value for $\mathrm{FEV}_{1}\left(\% \mathrm{FEV}_{1}\right)$ as independent predictors and each amino acid as dependent variable were examined using multiple linear regression analysis. Post hoc power analysis was used to verify the sample size for comparisons between groups.

\section{Results}

We obtained consent and collected blood from 33 hospitalized patients who met the selection criteria for AECOPD. Eleven of these 33 patients did not have bacterial infection (group A; including 2 patients who were diagnosed to have influenza A within 2 days of onset) and 13 had bacterial infection (group B). The remaining nine subjects were excluded. They were considered AECOPD with bacterial infection from clinical data, but no etiologic bacteria were detected. We were able to obtain consent and samples from 26 patients with COPD in a stable state who served as controls (group C). There was no significant betweengroup difference in the age or gender distribution between the study groups (Table 1). There was also no significant difference in the proportions of patients in the AECOPD groups who had eaten before collection of the blood samples (Table 2).

Patients without bacterial infection received noninvasive nasal ventilation, if needed, and medication with crystalloid solution before blood sampling. Patients with bacterial infection received medication with crystalloid solution and antibiotics before blood sampling. Both groups of patients were served a similar meal. No patients received medication with systemic corticosteroids.

The etiologic agents in group B were Streptococcus pneumoniae, Haemophilus influenzae, Klebsiella pneumoniae,
Table I Mean patient age in each study group

\begin{tabular}{|l|l|l|}
\hline Group & Patients (female), $\mathbf{n}$ & Mean age, years \\
\hline A & II (2) & $78.1 \pm 5.22$ \\
\hline B & I3 (I) & $79.9 \pm 9.95$ \\
\hline C & $26(I)$ & $73.9 \pm 7.91$ \\
\hline
\end{tabular}

Notes: Numeric values are expressed as the mean \pm SD. There were no significant intergroup differences. A, AECOPD without bacterial infection (group A); B, AECOPD with bacterial infection (group B); C, COPD in a stable state, control (group C). Abbreviation: AECOPD, acute exacerbation of COPD.

Staphylococcus aureus, and others (in four, three, two, two, and two patients, respectively).

The distributions for patient age, $\mathrm{FEV}_{1} \%, \% \mathrm{FEV}_{1}$, BMI, total protein, and serum albumin are shown in Figure 1. There was no statistically significant difference between the groups except for $\% \mathrm{FEV}_{1}, \mathrm{BMI}$, and serum albumin between groups $\mathrm{C}$ and $\mathrm{B}(P<0.05)$. Therefore, for groups $\mathrm{A}$ and $\mathrm{B}$ combined, we examined relationships between BMI, albumin, or $\mathrm{FEV}_{1}$ and each amino acid using multiple linear regressions (Table 3). Concentrations of phenylalanine were related to $\mathrm{BMI}$ and $\% \mathrm{FEV}_{1}$, glutamic acid with albumin, and tryptophan with albumin and $\% \mathrm{FEV}_{1}$. The levels of isoleucine, leucine, methionine, ornithine, and tyrosine were related to $\% \mathrm{FEV}_{1}$.

The distributions of levels of total amino acids, the 9 essential amino acids, and the 13 nonessential amino acids are shown in Figure 2. There were statistically significant differences in levels between groups $\mathrm{C}$ and $\mathrm{A}$ for only three amino acids (glycine, phenylalanine, and arginine). In contrast, there were statistically significant differences in levels between groups $\mathrm{C}$ and $\mathrm{B}$ for total amino acids and 13 amino acids. Levels of total amino acids and seven amino acids (asparagine, citrulline, glutamine, histidine, methionine, serine, and threonine) were lower in group B than in group A. The ratio of these amino acids in group B to group C (Table 4 ) was $<70 \%$ of the control for four amino acids (citrulline, histidine, serine, and threonine) and $83 \%$ or less for the other three amino acids. Post hoc power analysis for these seven amino acids and for total amino acids showed that the numbers of patients were sufficient for statistical comparisons between groups A and B (Table 5).

Table 2 Eating rate in the study groups

\begin{tabular}{|l|l|l|}
\hline Group & $\mathbf{0 \% - 4 9 \%}$ & $\mathbf{5 0 \% - 1 0 0 \%}$ \\
\hline $\mathrm{A}, \mathrm{n}$ & 3 & 8 \\
\hline $\mathrm{B}, \mathrm{n}$ & 4 & 9 \\
\hline
\end{tabular}

Notes: There were no significant intergroup differences. A, AECOPD without bacterial infection (group A); B, AECOPD with bacterial infection (group B). Abbreviation: AECOPD, acute exacerbation of COPD. 

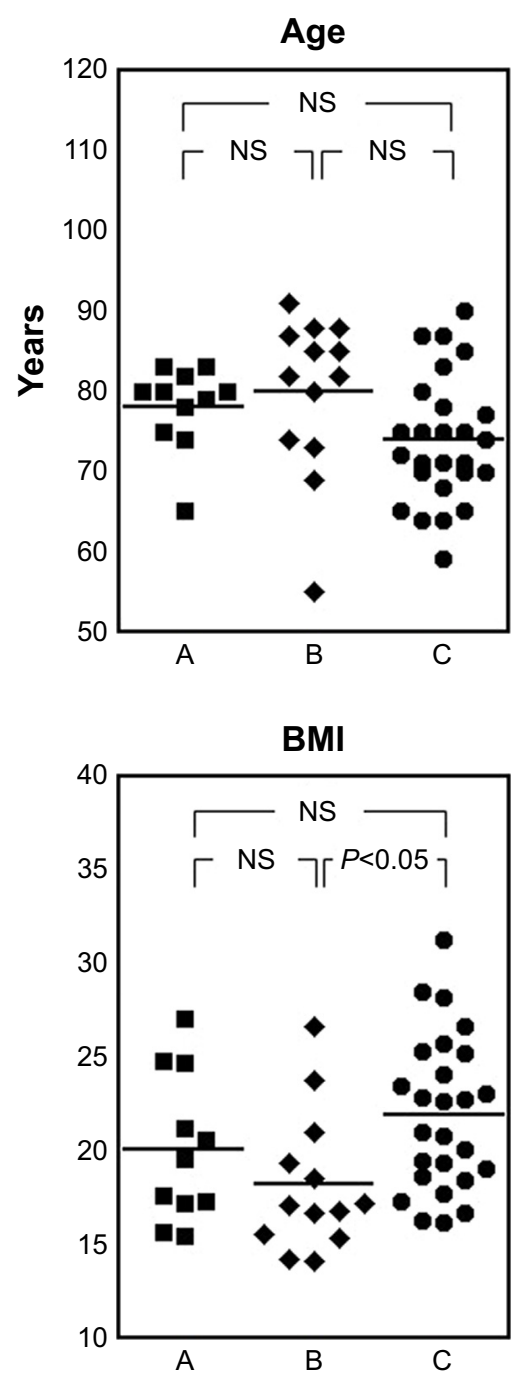
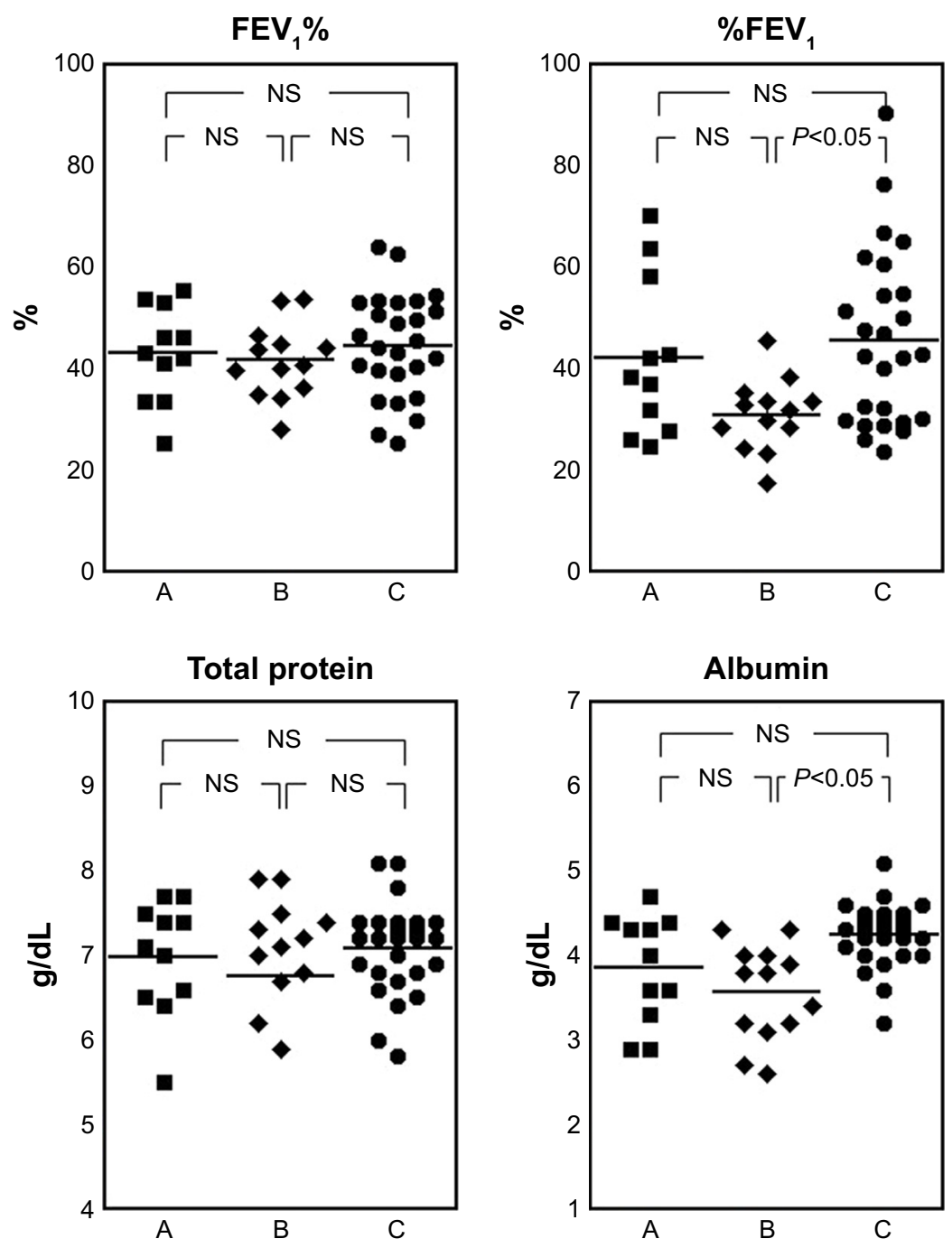

Figure I Body mass index and total serum protein, serum albumin, and C-reactive protein levels in each study group.

Notes: The horizontal solid lines show the mean values in each group. The statistical analysis was performed using the Steel-Dwass method. A, AECOPD without bacterial infection (group A); B, AECOPD with bacterial infection (group B); C, COPD in a stable state, control (group C).

Abbreviations: AECOPD, acute exacerbation of COPD; FEV \%, forced expiratory volume in I second; \%FEV , percentage of predicted value for FEV ${ }_{1}$; NS, not statistically significant.

Glycine and arginine levels were lower in the AECOPD groups ( $\mathrm{A}$ and $\mathrm{B}$ ) than in group $\mathrm{C}$ and were also lower in group B than in group A. Levels of three amino acids (alanine, tryptophan, and lysine) were lower in group B than in group C. The aspartic acid level was higher in group B than in group $\mathrm{C}$. The phenylalanine level was higher in both AECOPD groups ( $\mathrm{A}$ and $\mathrm{B}$ ) than in group $\mathrm{C}$, but there was no difference between groups A and B. Furthermore, there was no difference in three branched-chain amino acids (BCAAs) (valine, leucine, and isoleucine) or in cystine, glutamic acid, proline, ornithine, or tyrosine between the groups. The capacity for nitric oxide (NO) synthesis compared using the global arginine bioavailability ratio (GABR; ${ }^{23}$ defined as arginine/[ornithine + citrulline], was lower in the AECOPD groups [A and B] than in group C [Figure 3]).

\section{Discussion}

\section{Diagnosis and selection of subjects}

Infections, including bacterial and viral infections, are estimated to cause $50 \%-70 \%$ of AECOPD, ${ }^{24}$ and AECOPD without a clear cause is reported to occur at a rate of about $30 \% .{ }^{24}$ Bacterial infection and viral infection cannot be easily distinguished as AECOPD at the time of admission to hospital. ${ }^{4}$ Therefore, in this study, we only classified patients in whom etiologic bacteria could be detected as having AECOPD with bacterial infection (group B) rather than those in whom bacterial infection was suspected on the basis of clinical symptoms and test results. In contrast, we classified patients who did not satisfy any of the selection criteria except for fever as having AECOPD without bacterial infection (group A). The nine excluded cases were 
Table 3 Multiple linear regression analysis for each amino acid to BMI, albumin, and \%FEV,

\begin{tabular}{|c|c|c|c|c|c|c|}
\hline \multirow[t]{2}{*}{ Amino acid } & \multicolumn{2}{|l|}{ BMI } & \multicolumn{2}{|c|}{ Albumin } & \multicolumn{2}{|l|}{$\% \mathrm{FEV}_{1}$} \\
\hline & SPRC & $P$-value & SPRC & $P$-value & SPRC & $P$-value \\
\hline Total amino acids & -0.0151 & NS & 0.3540 & NS & 0.3330 & NS \\
\hline Alanine & -0.0253 & NS & 0.3578 & NS & 0.2688 & NS \\
\hline Arginine & -0.0063 & NS & 0.2076 & NS & 0.3009 & NS \\
\hline Asparagine & 0.0355 & NS & 0.1681 & NS & 0.3563 & NS \\
\hline Aspartic acid & 0.0394 & NS & 0.1293 & NS & 0.0760 & NS \\
\hline Citrulline & -0.0990 & NS & 0.2353 & NS & -0.2030 & NS \\
\hline Cystine & -0.0776 & NS & 0.1586 & NS & 0.3808 & NS \\
\hline Glycine & -0.0630 & NS & 0.0453 & NS & 0.4066 & NS \\
\hline Glutamine & -0.0396 & NS & 0.4202 & NS & 0.0786 & NS \\
\hline Glutamic acid & 0.2965 & NS & 0.6426 & $<0.01$ & 0.0726 & NS \\
\hline Histidine & -0.0086 & NS & 0.0182 & NS & 0.1317 & NS \\
\hline Isoleucine & -0.0162 & NS & 0.0636 & NS & 0.4847 & $<0.05$ \\
\hline Leucine & -0.2177 & NS & 0.1295 & NS & 0.4552 & $<0.05$ \\
\hline Lysine & 0.1104 & NS & 0.1490 & NS & 0.138 & NS \\
\hline Methionine & -0.1781 & NS & 0.1768 & NS & 0.5474 & $<0.05$ \\
\hline Ornithine & -0.1390 & NS & -0.1803 & NS & 0.2480 & NS \\
\hline Phenylalanine & -0.4507 & $<0.05$ & -0.1849 & NS & 0.5842 & $<0.01$ \\
\hline Proline & 0.1395 & NS & 0.2133 & NS & 0.2118 & NS \\
\hline Serine & -0.1125 & NS & 0.1500 & NS & 0.4255 & NS \\
\hline Threonine & 0.0934 & NS & 0.1884 & NS & 0.3230 & NS \\
\hline Tryptophan & -0.1388 & NS & 0.4474 & $<0.05$ & 0.4078 & $<0.05$ \\
\hline Tyrosine & -0.1068 & NS & 0.1286 & NS & 0.5897 & $<0.01$ \\
\hline Valine & -0.01683 & NS & 0.0896 & NS & 0.3545 & NS \\
\hline
\end{tabular}

Notes: Multiple linear regression analysis for each amino acid, combined group A and group B; NS, $P>0.05$.

Abbreviations: BMI, body mass index; \%FEV , percentage of predicted value for forced expiratory volume in I second; NS, not statistically significant; SPRC, standardized partial regression coefficient.

suspected of having bacterial infection from their clinical symptoms and clinical test results, but we could not detect any bacteria that might conceivably be the etiologic agent. The etiologic agent for community-acquired pneumonia is reportedly detected on bacterial culture in $20 \%-49 \%$ of cases in Japan. ${ }^{25} S$. pneumoniae is reported to be the most common etiologic agent, followed by $\mathrm{H}$. influenzae. ${ }^{25}$ The etiologic agents detected in this study followed a similar trend.

\section{Measurements obtained}

Blood was collected after $\sim 12$ hours of fasting in group C. However, in the AECOPD groups, it was performed 2-3 hours after eating as a nonfasting collection. This is because the AECOPD groups could not fast to prioritize their treatment. Plasma amino acids may increase in response to dietary intake, but amino acid levels were lower in our patients with AECOPD (groups A and B) than in the controls (group C), except for phenylalanine and aspartic acid. There was no difference in the eating rate in the medical records between groups A and B, and the decreased amino acid levels were lower in group $B$ than in group A. On the basis of these observations, we consider that the difference between group $A$ and group B was not an effect of dietary intake. In young Japanese adults, it has been reported that amino acid levels return to predose values 2 hours after oral intake of BCAAs. ${ }^{26}$ There have been two reports on plasma amino acid concentrations in Japanese patients with COPD in a stable state, ${ }^{27,28}$ and the results in group $\mathrm{C}$ in our study (excluding glutamic acid, histidine, and threonine) are similar to those in one of the earlier reports. ${ }^{28} \mathrm{BCAA}$ levels are reported to be lower in individuals with COPD in a stable state. ${ }^{27} \mathrm{We}$ found that isoleucine and leucine concentrations were influenced by $\% \mathrm{FEV}_{1}$ (Table 3), and considered these results to be related to the reported relationship between the ratio of BCAA//aromatic amino acids) and $\mathrm{FEV}_{1}{ }^{27} \mathrm{~A}$ detailed previous comparison between nonpneumonic and pneumonic AECOPD $^{5}$ showed that $\% \mathrm{FEV}_{1}$ was lower in nonpneumonic than in pneumonic AECOPD, but our results did not support this relationship. 

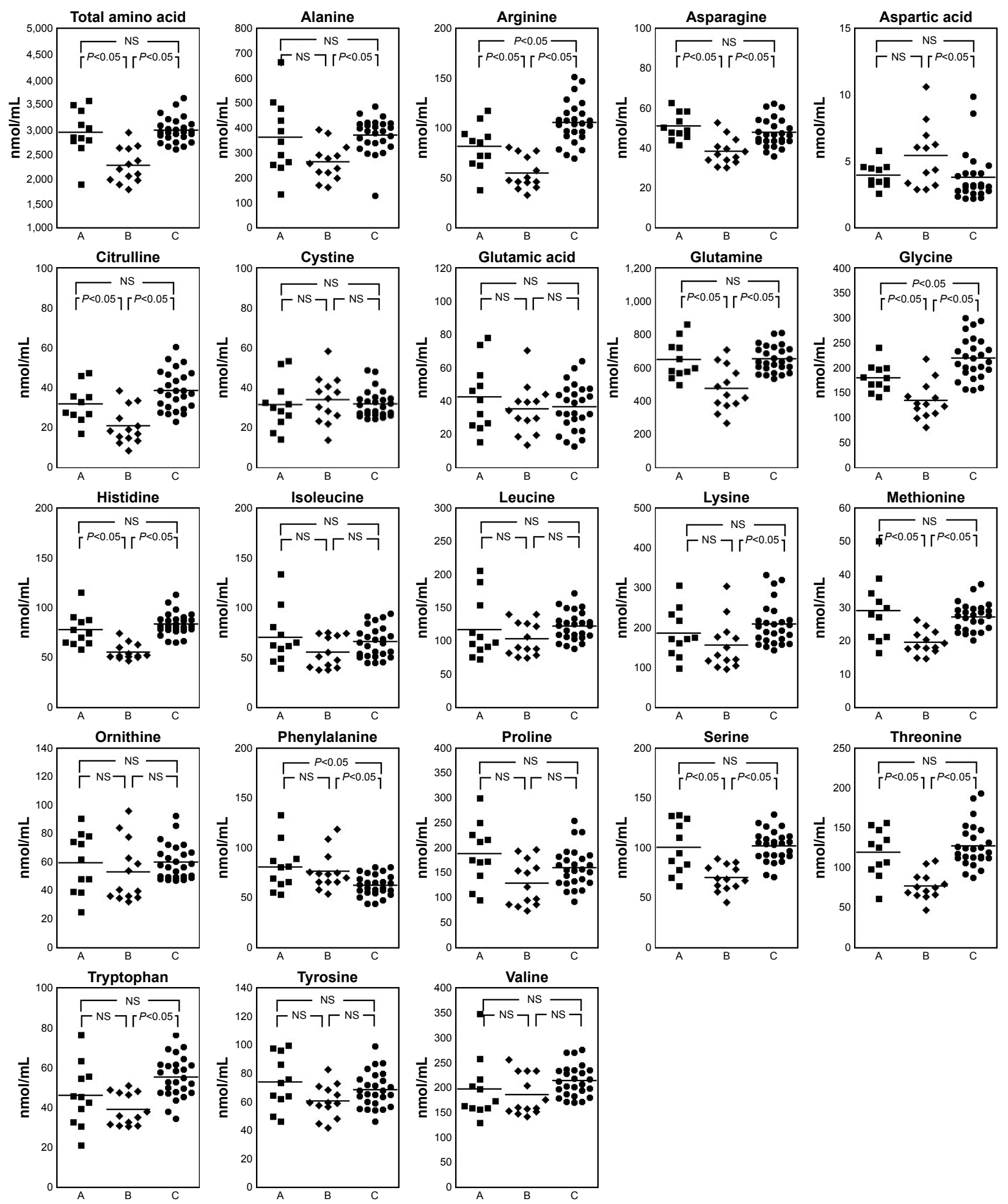

Figure 2 Intergroup comparisons for each amino acid.

Notes: The horizontal solid lines show the mean values in each group. The statistical analysis was performed using the Steel-Dwass method. A, AECOPD without bacterial infection (group A); B, AECOPD with bacterial infection (group B); C, COPD in a stable state, control (group C).

Abbreviations: AECOPD, acute exacerbation of COPD; NS, not statistically significant.

The dynamics and clinical significance of changes in amino acid levels in patients with AECOPD are largely unknown. However, a decrease in the total amino acid level has been reported to start before the onset of infection-related loss of appetite and to have no causal relationship with a reduced dietary intake of protein. ${ }^{7}$ In this study, the total amino acid levels were lower only in group B, which we could not attribute to dietary intake. Of the seven amino acids 
Table 4 Ratio of amino acids in AECOPD (groups A and B) to stable COPD (group C)

\begin{tabular}{|l|l|l|}
\hline & Group A & Group B \\
\hline Total amino acids & $98.3 \%$ & $77.4 \%$ \\
\hline Asparagine & $106.6 \%$ & $75.5 \%$ \\
\hline Citrulline & $82.5 \%$ & $56.0 \%$ \\
\hline Glutamine & $99.2 \%$ & $83.0 \%$ \\
\hline Histidine & $92.6 \%$ & $71.8 \%$ \\
\hline Methionine & $106.5 \%$ & $67.6 \%$ \\
\hline Serine & $98.4 \%$ & $69.8 \%$ \\
\hline Threonine & $93.4 \%$ & $65.2 \%$ \\
\hline
\end{tabular}

Note: Numeric values are the percentage of each amino acid level in patients with COPD that was stable (group C).

Abbreviation: AECOPD, acute exacerbation of COPD.

that were observed to decrease in group B, four decreased to $<70 \%$ of the value in group $\mathrm{C}$ and three to $<83 \%$ (Table 3); in comparison, the levels in group A were within the range of $92.6 \%-106.6 \%$ of those in group C, except for citrulline (Table 3). Only methionine was correlated with $\% \mathrm{FEV}_{1}$. Other amino acids were not related to BMI, albumin, or $\% \mathrm{FEV}_{1}$. These results suggest that levels of six of the amino acids (ie, asparagine, citrulline, glutamine, histidine, serine, and threonine) decrease greatly in the acute phase of bacterial infection.

Immunonutrition has recently been introduced as a concept in nutritional intervention and emphasizes the importance of arginine and glutamine. ${ }^{29}$ In this study, arginine levels were lower in the patients with AECOPD (groups A and B), as was the glutamine level in the patients with bacterial infection (group B). One recent report showed an association between the severity of COPD and changes in arginine metabolism. ${ }^{30}$ Another report showed that endogenous production of arginine was upregulated but was unrelated to wholebody NO production in patients with moderate-to-severe

Table 5 Results of post hoc analysis

\begin{tabular}{|l|l|l|}
\hline & $\begin{array}{l}\text { Required sample size } \\
\text { for each group }\end{array}$ & Post hoc power \\
\hline Total amino acids & 6 & $97.2 \%$ \\
\hline Asparagine & 5 & $99.5 \%$ \\
\hline Citrulline & 10 & $81.0 \%$ \\
\hline Glutamine & 8 & $92.8 \%$ \\
\hline Histidine & 6 & $98.2 \%$ \\
\hline Methionine & 9 & $86.5 \%$ \\
\hline Serine & 7 & $93.9 \%$ \\
\hline Threonine & 6 & $98.4 \%$ \\
\hline
\end{tabular}

Notes: Required sample size was calculated from mean value and SD of each amino acid, setting as alpha err $=0.05$ and power $=0.80$. Post hoc statistical power was calculated from the mean value and SD of each amino acid with actual sample size (group $A=\mid 1$, group $B=\mid 3$ ).

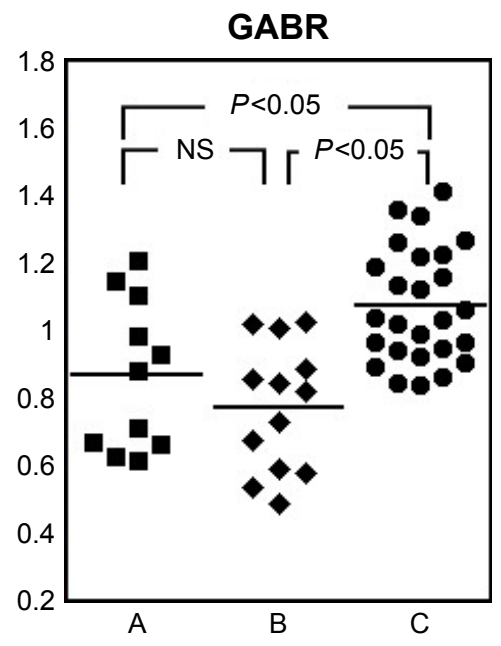

Figure 3 Global arginine bioavailability ratio in each group.

Notes: The horizontal solid lines show the mean values in each group. The statistical analysis was performed using the Steel-Dwass method. A, AECOPD without bacterial infection (group A); B, AECOPD with bacterial infection (group B); $C$, COPD in a stable state, control (group $C$ ).

Abbreviations: AECOPD, acute exacerbation of COPD; GABR, global arginine bioavailability ratio; NS, not statistically significant.

COPD.${ }^{31}$ It has been suggested that the capacity to synthesize NO should be assessed by the GABR rather than the systemic arginine level. ${ }^{23}$ The GABR was lower in the patients with AECOPD (groups A and B) than in the controls (group C), and there was no difference in this ratio between groups $\mathrm{A}$ and $\mathrm{B}$. These findings suggest that there is a decrease in both plasma arginine levels and the capacity to synthesize NO in patients with AECOPD, regardless of whether or not bacterial infection is present. A review of the relationship between glutamine and various respiratory diseases highlights the important role of the lungs in glutamine homeostasis, which is therefore altered in various pulmonary diseases. ${ }^{32}$

There have been reports concerning the dynamics of glycine and methionine specifically in relation to bacterial infection. ${ }^{33,34}$ Glycine is known to be involved in antiinflammatory activity and the immune response, ${ }^{33}$ and methionine is an essential amino acid for numerous organisms, including bacteria. ${ }^{34}$ Therefore, it is possible that these changes in amino acid levels are a physiologically normal reaction to bacterial infection. Glycine levels have been reported to increase when influenza is complicated by bacterial infection ${ }^{6}$ and in severe infectious disorders such as sepsis. ${ }^{35}$ However, in this study, glycine levels decreased in patients with AECOPD (groups A and B).

At the time of infection, there is an increase in release of tryptophan from skeletal muscles in response to increased catabolism and decreased anabolism, and this tryptophan is immediately taken up by the liver and used for protein synthesis in plasma. ${ }^{7}$ Recent research has shown that tryptophan 
levels decrease in patients with AECOPD regardless of whether the infection is bacterial or nonbacterial. ${ }^{36}$ According to recent reports, activation of indoleamine 2,3-dioxygenase and catabolism of tryptophan occur at times of infection and trigger anti-inflammatory activity in the lungs. ${ }^{37}$ In the present study, there was no significant difference in the plasma concentration of tryptophan between groups A and B; however, the level was lower in group B than in group C.

In contrast, phenylalanine is known to increase in response to inflammation, including that caused by bacterial infection and viral infection, ${ }^{38}$ and the details of this have been elucidated. ${ }^{7}$ In this study, the plasma phenylalanine level was increased in patients with AECOPD (groups A and B).

Amino acids are directly involved in cell metabolism and also operate as neurotransmitters. ${ }^{39}$ Serine, levels of which decreased markedly only in group B, has an inhibitory effect in the central nervous system, and glycine, which decreased in groups $\mathrm{A}$ and $\mathrm{B}$, also has an inhibitory effect. ${ }^{39}$ Aspartic acid is one of the amino acids with an excitatory effect, and an increase in aspartic acid ${ }^{39}$ was observed in group B. This means that amino acid levels in group B changed in a direction that increased excitability in the central nervous system.

\section{General comments}

The above-mentioned findings indicate that differences in amino acid levels at the time of hospitalization for AECOPD are likely to be associated with bacterial infection. We think that these decreased amino acids (ie, asparagine, citrulline, glutamine, histidine, methionine, serine, and threonine) have potential utility as diagnostic markers to distinguish between bacterial and nonbacterial AECOPD. However, further research is needed to investigate the time course and clinical significance of changes in the individual amino acids associated with AECOPD.

COPD involves inflammation not only in the lungs but also throughout the entire body, including the skeletal muscles. ${ }^{40,41}$ Therefore, it is considered that inflammation and changes in amino acid metabolism related to AECOPD affect the skeletal muscles, so rehabilitation probably requires individualized approaches. In addition, amino acids are essential nutrients for infectious microorganisms, ${ }^{34}$ and levels of some amino acids such as tryptophan decrease in response to infection and/or inflammation. ${ }^{37}$ One study showed that arginine supplementation had adverse effects in sepsis related to pneumonia. ${ }^{42}$ Trends in amino acid values in patients with AECOPD and their clinical significance will require further study.

\section{Limitations}

The COPD phenotype in AECOPD ${ }^{43,44}$ should have been considered but was not included in our analysis. Furthermore, there was no investigation of the duration of the decrease in plasma amino acid levels that occurred in response to bacterial infection. This question is being addressed in a current investigation by our group.

\section{Conclusion}

Our results suggest that specific amino acids (ie, asparagine, citrulline, glutamine, histidine, serine, and threonine) have potential utility as diagnostic markers to distinguish between bacterial and nonbacterial AECOPD. In addition, consideration must be given to distinguishing whether or not bacterial infection is present when embarking on rehabilitation and/or nutritional intervention for patients with AECOPD.

\section{Acknowledgments}

We would like to thank Editage (https://www.editage.jp) for English-language editing and SRL, Inc. (http://www. srl-group.co.jp/english/index.html) for analyzing the amino acids.

\section{Author contributions}

HI had full access to the study data, takes full responsibility for the integrity of the data and the accuracy of the analysis, and contributed to the study design. SI contributed to the nutritional management of patients. All authors contributed to data analysis, drafting and revising the article, gave final approval of the version to be published, and agree to be accountable for all aspects of the work.

\section{Disclosure}

The authors report no conflicts of interest in this work.

\section{References}

1. Donaldson GC, Seemungal TA, Bhowmik A, Wedzicha JA. Relationship between exacerbation frequency and lung function decline in chronic obstructive pulmonary disease. Thorax. 2002;57(10):847-852.

2. Miravitlles M, Espinosa C, Fernández-Laso E, et al. Relationship between bacterial flora in sputum and functional impairment in patients with acute exacerbations of COPD. Study Group of bacterial infection in COPD. Chest. 1999;116(1):40-46.

3. Greenberg SB, Allen M, Wilson J, Atmar RL. Respiratory viral infections in adults with and without chronic obstructive pulmonary disease. Am J Respir Crit Care Med. 2000;162(1):167-173.

4. Sapey E, Stockley RA. COPD exacerbations 2: Aetiology. Thorax. 2006; 61(3):250-258.

5. Arturo H, Ernesto C, Rosario M, et al. Pneumonic and nonpneumonic exacerbations of COPD. Chest. 2013;144(4):1134-1142.

6. Mohammad MB, Hans JV, Aalim MW, et al. Canadian Critical care translational biology group (CCCTBG). Plasma metabolomics for the diagnosis of H1N1 influenza pneumonia. Crit Care. 2017;21:97. 
7. Wannemacher RW. Key role of various individual amino acids in host response to infection. Am J Clin Nutr. 1977;30(8):1269-1280.

8. Anthonisen NR, Manfreda J, Warren CP, et al. Antibiotic therapy in exacerbations of chronic obstructive pulmonary disease. Ann Intern Med. 1987;106(2):196-204.

9. Rodriguez-Roisin R. Toward a consensus definition for COPD exacerbations. Chest. 2000;117(5 Suppl 2):398S-4015S.

10. Global Initiative for Chronic Obstructive Lung Disease. Global strategy for the diagnosis, management and prevention of COPD; 2017. Available from: http://goldcopd.org/gold-2017-global-strategy-diagnosismanagement-prevention-copd/. Accessed January 8, 2017.

11. Pulmonary rehabilitation: joint ACCP/AACVPR evidence-based guidelines. ACCP/AACVPR pulmonary rehabilitation guidelines panel. American College of chest physicians. American Association of cardiovascular and pulmonary rehabilitation. Chest. 1997;112(5):1363-1396.

12. Sugawara K, Takahashi H, Kasai C, et al. Effects of nutritional supplementation combined with low-intensity exercise in malnourished patients with COPD. Respir Med. 2010;104(12):1883-1889.

13. Ferreira IM, Brooks D, White J, Goldstein R. Nutritional supplementation for stable chronic obstructive pulmonary disease. Cochrane Database Syst Rev. 2012;12:CD000998.

14. Collins PF, Stratton RJ, Elia M. Nutritional support in chronic obstructive pulmonary disease: a systematic review and meta-analysis. Am J Clin Nutr. 2012;95(6):1385-1395.

15. Greening NJ, Williams JEA, Hussain SF, et al. An early rehabilitation intervention to enhance recovery during hospital admission for an exacerbation of chronic respiratory disease: randomised controlled trial. BMJ. 2014;349:g4315.

16. Matsui H, Jo T, Fushimi K, Yasunaga H. Outcomes after early and delayed rehabilitation for exacerbation of chronic obstructive pulmonary disease: a nationwide retrospective cohort study in Japan. Respir Res. 2017;18(1):68.

17. Helga SU, James GM, Katherine GD. Impact of nutritional support on functional status during an acute exacerbation of chronic obstructive pulmonary disease. Am J Respir Crit Care Med. 1997;a56:794-799.

18. Japanese Respiratory Society. [The JRS Guidelines for the Management of COPD 2018]. Tokyo, Japan: Japanese Respiratory Society; 2018. Japanese.

19. Ethical guidelines for medical and health research involving human subjects. Ministry of health, labour and welfare of Japan; 2015. Available from: http://www.mhlw.go.jp/file/06-Seisakujouhou-10600000-Daijin kanboukouseikagakuka/0000080278.pdf. Accessed January 8, 2017.

20. Stockley RA, O'Brien C, Pye A, Hill SL. Relationship of sputum color to nature and outpatient management of acute exacerbations of COPD. Chest. 2000;117(6):1638-1645.

21. Niederman MS, Mandell LA, Anzueto A, et al. Guidelines for the management of adults with community-acquired pneumonia. Diagnosis, assessment of severity, antimicrobial therapy, and prevention. Am J Respir Crit Care Med. 2001;163(7):1730-1754.

22. Müller B, Harbarth S, Stolz D, et al. Diagnostic and prognostic accuracy of clinical and laboratory parameters in community-acquired pneumonia. BMC Infect Dis. 2007;7:10.

23. Tang WH, Wang Z, Cho L, Brennan DM, Hazen SL. Diminished global arginine bioavailability and increased arginine catabolism as metabolic profile of increased cardiovascular risk. J Am Coll Cardiol. 2009;53(22): 2061-2067.

24. Sapey E, Stockley RA. COPD exacerbations. 2: aetiology. Thorax. 2006;61(3):250-258

International Journal of COPD

\section{Publish your work in this journal}

The International Journal of COPD is an international, peer-reviewed journal of therapeutics and pharmacology focusing on concise rapid reporting of clinical studies and reviews in COPD. Special focus is given to the pathophysiological processes underlying the disease, intervention programs, patient focused education, and self management protocols.
25. Japanese Respiratory Society. [The JRS guideline for management of pneumonia in adults 2017]. Tokyo, Japan: Japanese Respiratory Society; 2017. Japanese.

26. Zhang Y, Kobayashi H, Mawatari K, et al. Effects of branched-chain amino acid supplementation on plasma concentrations of free amino acids, insulin, and energy substrates in young men. J Nutr Sci Vitaminol. 2011;57(1):114-117.

27. Yoneda T, Yoshikawa M, Fu A, et al. Plasma levels of amino acids and hypermetabolism in patients with chronic obstructive pulmonary disease. Nutrition. 2001;17(2):95-99.

28. Kutsuzawa T, Shioya S, Kurita D, Haida M. Plasma branched-chain amino acid levels and muscle energy metabolism in patients with chronic obstructive pulmonary disease. Clin Nutr. 2009;28(2):203-208.

29. McCowen KC, Bistrian BR. Immunonutrition: problematic or problem solving? Am J Clin Nutr. 2003;77(4):764-770.

30. Jonker R, Deutz NE, Erbland ML, Anderson PJ, Engelen MP. Alterations in whole-body arginine metabolism in chronic obstructive pulmonary disease. Am J Clin Nutr. 2016;103(6):1458-1464.

31. Wannemacher RW, Klainer AS, Dinterman RE, Beisel WR. The significance and mechanism of an increased serum phenylalanine-tyrosine ratio during infection. Am J Clin Nutr. 1976;29(9):997-1006.

32. Oliveira G, de Abreu M, Pelosi P, Rocco P. Exogenous glutamine in respiratory diseases: myth or reality? Nutrients. 2016;8(2):76.

33. Zhong Z, Wheeler MD, Li X, et al. L-glycine: a novel antiinflammatory, immunomodulatory, and cytoprotective agent. Curr Opin Clin Nutr Metab Care. 2003;6(2):229-240.

34. Basavanna S, Chimalapati S, Maqbool A, et al. The effects of methionine acquisition and synthesis on Streptococcus pneumoniae growth and virulence. PLoS One. 2013;8(1):e49638.

35. Longxiang S, Hua L, Aimei X, et al. Dynamic changes in amino acid concentration profiles in patients with sepsis. PLoS One. 2015;10: $\mathrm{e} 0121933$

36. Gulcev M, Reilly C, Griffin TJ, et al. Tryptophan catabolism in acute exacerbations of chronic obstructive pulmonary disease. Int J Chron Obstruct Pulmon Dis. 2016;11:2435-2446.

37. Suzuki Y, Suda T, Yokomura K, et al. Serum activity of indoleamine 2,3-dioxygenase predicts prognosis of community-acquired pneumonia. J Infect. 2011;19:436-442.

38. Zinellu A, Fois AG, Sotgia S, et al. Arginines plasma concentration and oxidative stress in mild to moderate COPD. PLoS One. 2016;11(8): $\mathrm{e} 0160237$.

39. Brunton L, Chabner BA, Knollman B. Goodman and Gilman's The Pharmacological Basis of Therapeutics. 12th ed. New York, NY: McGraw-Hill Education/Medical; 2011.

40. Agustí AG, Noguera A, Sauleda J, et al. Systemic effects of chronic obstructive pulmonary disease. Eur Respir J. 2003;21(2):347-360.

41. Soriano JB, Visick GT, Muellerova H, Payvandi N, Hansell AL. Patterns of comorbidities in newly diagnosed COPD and asthma in primary care. Chest. 2005;128(4):2099-2107.

42. Dent DL, Heyland DK, Levy H. Immunonutrition may increase mortality in critically ill patients with pneumonia: results of a randomized trial. Crit Care Med. 2002;30(Suppl):A17.

43. Hurst JR. Exacerbation phenotyping in chronic obstructive pulmonary disease. Am J Respir Crit Care Med. 2011;184(6):625-626.

44. Zhou A, Zhou Z, Zhao Y, Chen P. The recent advances of phenotypes in acute exacerbations of COPD. Int J Chron Obstruct Pulmon Dis. 2017; 12:1009-1018.

\section{Dovepress}

This journal is indexed on PubMed Central, MedLine and CAS. The manuscript management system is completely online and includes a very quick and fair peer-review system, which is all easy to use. Visit http://www.dovepress.com/testimonials.php to read real quotes from published authors. 